\title{
Biomass - alternative renewable energy source and its conversion for hydrogen rich gas production
}

\author{
Elena David ${ }^{1}{ }^{1}$, Janez $\mathrm{K}_{\text {opac }}^{2}$, Adrian A rmeanu ${ }^{1}$, Violeta $\mathrm{Niculescu}^{1}$, Claudia Sandru${ }^{1}$,Viorel Badescu ${ }^{3}$ \\ ${ }^{1}$ N ational Research Institute for Cryogenic \& I sotopic Technologies, U zinei N 0.4; P.O.Raureni, P.O.B ox 7; 240050 R m.V alcea, Romania \\ ${ }^{2}$ F aculty of M echanical Engineering, University of L jubljana, A skerceva 6, 1000 Ljubljana, Slovenia \\ ${ }^{3}$ Polytechnic University of Bucharest, Splaiul Independenței 313, Bucharest, 060042, R omania
}

\begin{abstract}
This paper presnts biomass as a renewable energy source and defines the resources as well as the ways through biomass energy is converted into fuels, the technologies used for extracting the energy from biomass as well as the advantages and disadvantages that appear by using of biomass as a energy source. In addition,it is known hydrogen is an important alternative energy vector and a bridge to a sustainable way fot the energy future. Hydrogen is an energy carrier and can be obtained by different production technologies from a large variety of primary energy sources. At present, many researches are focused on getting energy from biomass, a sustainable and non-polluting way to replace fossil fuels, because the biomass can be considered as the best option with high potential, which meets energy requirements and could insure fuel supply in the future. Biomass and residual biomass can be used to produce hydrogen rich gas sustainably. Biomass pyrolysis and gasification offers an efficiency and economical route for the renewable hydrogen production and this is al so discussed in the paper.
\end{abstract}

\section{Introduction}

Biomass is a source of raw material and this term describes all organic matter resulted by photosynthesis. Biomass includes all land and water-based vegetation and trees, and also all waste biomass such as forestry and agricultural residues, municipal bio-solids (sewage), municipal solid waste (M SW), animal wastes (manures), and certain types of industrial wastes. The energy markets are heavily dependent on fossil fuels which are limited reserves, so new sources must be found to replace fossil fuels. In this context, biomass is other naturally source containing carbon resource that is enough in quantity to be used as a substitute for fossil fuels [1].Through the photosynthesis process, chlorophyll into plants storages the energy of the sun by converting $\mathrm{CO}_{2}$ from the environment into carbohydrates (i.e., complex compounds composed of $\mathrm{C}, \mathrm{H}$, and $\mathrm{O}$ ). When these complex compounds are burned, they turn back into $\mathrm{CO}_{2}$ and $\mathrm{H}_{2} \mathrm{O}$ and release the energy they contain. By the comparison, in this way, the biomass could function as a sort of natural battery for the storing of solar energy [2] and a potential source of $\mathrm{H}_{2}$ as a future solution [3]. The use of the biomass energy form has played a key role during the mankind evolution and until relatively recently it constituted the only form of energy which was exploited by people and is still the main energy source for more than half the population in the world for the domestic energy needs [4]. One of the simple forms of biomass use is a basic open fire to provide heat for cooking, warming water or home warming. In the present there are technologies for the extracting energy and converting it into useful power or heat in an efficient way with positive environment impact and there is expected to be the driving forces that stimulate the transformation of biomass into one of the dominant energy resources [5]. Unlike fossil fuels, the biomass is renewable and a short time is needed to replace what is used as an energy resource. Biomass also is the renewable energy source that releases $\mathrm{CO}_{2}$ in use, but however the $\mathrm{CO}_{2}$ release is compensated by the fact that the biomass growing uses the $\mathrm{CO}_{2}$ from environmenr to capture energy during photosynthesis process. When the biomass resource is being used sustainably, there are not carbon emissions over the time frame of a cycle of biomass production [6]. Figure 1 presents two environmentally friendly schemes for a biomass energy cycle and the biomass way is used for energy generation [2]. In the present, many researches have been focused on sustainable and environmental friendly energy production from the biomass to replace fossil fuels [7]. On the other hand, hydrogen production is one of the most promising alternative energy technologies. Hydrogen is a secondary form of energy that must be manufactured like electricit, it is an energy carrier $[6,7]$. Hydrogen is produced from a variety of primary energy sources and by different production technologies. The most $\mathrm{H}_{2}$ is currently obtained from non-renewable sources such as natural gas, oil, and coal [8] and only $4 \%$ and $1 \%$ is generated from water using electricity and biomass, respectively [9]. $\mathrm{H}_{2}$ produced of renewable primary energy sources such as biomass is

Corresponding author: elenadavid2004@yahoo.com 
ideal for gradually replacing fossil fuels [10] because biomass and biomass derived fuels can be used to produce hydrogen sustainably. U sing biomass instead of fossil fuels to produce $\mathrm{H}_{2}$ reduces the $\mathrm{CO}_{2}$ amount released into the atmosphere, since the $\mathrm{CO}_{2}$ released when the biomass is gasified was previously absorbed from the atmosphere and fixed by photosynthesis process in the plant growing [10].

\section{Processes used for energy extracting from biomass}

B iomass can be converted to solid, liquid, gaseous fuels, thermal energy or other valuable chemical products through different conversion processes. Generally, the manly bio-power technologies are comprised of combustion and co-firing, gasification, pyrolysis, fermentation and anaerobic digestion.

The direct combustion is the simplest method of energy extracting from biomass and industrial biomass combustion systems burn many kinds of biomass fuel, including wood, agricultural wastes, municipal solid waste (M SW), wood pulping liquor, refuse-derived fuel etc. Biomass is burned to produce steam, then the steam turns a turbine and the turbine drives a generator that produces electricity. Because of potential ash build-up, which fouls boilers, the efficiency is reduced and the costs increase, and due to this only certain kinds of biomass materials are used for direct combustion.

The gasification is a process which transforms a solid fuel at high temperatures and a limited oxygen amount, into a gaseous fuel. The gas produced by this process ( Figure 1 ) is a mixture of gases such as $\mathrm{CO}, \mathrm{CO}_{2}, \mathrm{~N}_{2}, \mathrm{H}_{2}$, and $\mathrm{CH}_{4}$.
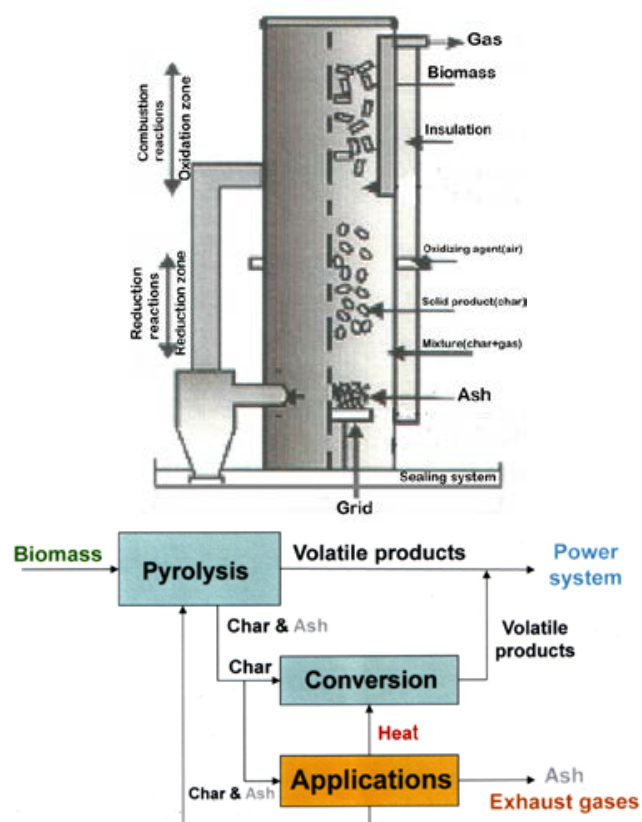

Figure 1. Schemes of a gasification process

The gas produced is then used to drive a high efficiency and combined cycle gas turbine. The gasification process has several advantages over combustion process, one of the resultant gases, $\mathrm{CH}_{4}$, can be considered in a similar way as natural gas, and used for the same applications. A nother advantage of gasification process is that it produces a fuel with fewer impurities because they have been removed and therefore causes fewer pollution problems when it is burnt. Under suitable parameters, gasification process can also produce syngas, a mixture of $\mathrm{CO}$ and $\mathrm{H}_{2}$ that can be used to obtain hydrocarbon (e.g., $\mathrm{CH}_{4}, \mathrm{CH}_{3} \mathrm{OH}$, etc.) for replacement fossil fuels. $\mathrm{H}_{2}$ itself is a potential fuel, without pollution, that can substitute petroleum and oil [7].

Pyrolysis process in simplest form, represents heating of the biomass to release the volatile products and leaving behind bio-oil and charcoal (Figure 2).

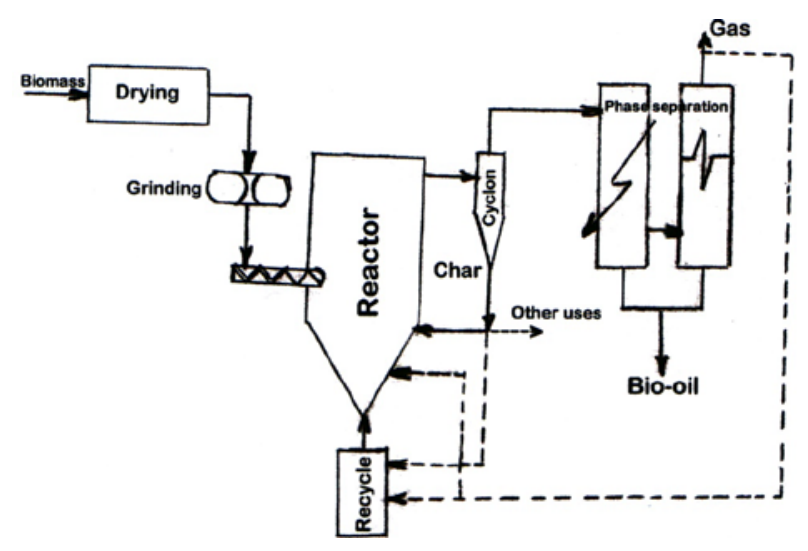

Figure 2. A scheme of representation of the pyrolysis process.

This process has doubled the energy density of the raw material because bio-oil and charcoal, which represents more than half the weight of the initial biomass, contains al most the same amount of energy and makes the fuel easier transportable. Also, the charcoal burns at a higher temperature than the raw biomass, making it much more useful for different applications. $M$ ore new pyrolysis methods are developed recently to storage volatile products that are otherwise lost to the system. From the collected volatiles can be produced a gas which is rich in hydrogen (as a potential fuel).

Fermentation process uses yeasts and other microorganisms to ferment the sugar of biomass into ethanol. The ethanol obtained through fermentation process is then mixed with diesel to produce diesehol, a product especially used by trucks and buses [7].

Biomass digestion process works by utilizing anaerobic bacteria and these microorganisms usually live at the bottom of sludges or in other places where the air is not present, consuming dead organic matter to produce $\mathrm{CH}_{4}$ and $\mathrm{H}_{2}$. By feeding organic matter such as sewage sludge into a tank, called digester, and adding bacteria, it can be collected the produced gas to use as an energy source.

\subsection{Advantages of biomass energy}

Some of the advantages of using biomass as a source of energy are: (i) biomass energy is an abundant, environmental friendly, secure and renewable source of energy; (ii) biomass does not increase $\mathrm{CO}_{2}$ to the 
atmosphere because it absorbs the same amount of carbon in growing as it releases when is used as a fuel; (iii) a major advantage of biomass is that it can be used to generate electricity using the same power plants that are used for the burning of fossil fuels; (iv) biomass fuels are sustainable, the green plants from which biomass fuels are obtained fix $\mathrm{CO}_{2}$ as they grow, and consequently does not increase the level of carbon in the atmosphere. In addition, using refuse as a fuel avoids polluting landfill disposal; (v) alcohols and other fuels produced by biomass are viable, efficient, and relatively clean burning; (vi) biomass is easily available and can be grown with relative ease in all the world.

\subsection{Impediments to biomass energy use}

The use of biomass energy encounters several impediments, such as:

(i) Biomass is still an expensive source of energy, both in terms of producing biomass and convertion it into product fuels, because a large quantity of biomass is needed;

(ii) On a small scale there is probably a loss of energy as a lot of energy must be used for the growing the plant mass and also the biomass is difficult to store in its raw form;

(iii) A n other disadvantage of biomass use is that direct biomass combustion could be harmful to the environment as burning biomass releases $\mathrm{CO}_{2}$, which contributes to the warming of the atmosphere and possible climate change. Also biomass burning creates soot and other air pollutants;

(iv).Excessive wood consumption can destroy forests, soils are easily eroded and do not hold rainfall.Also increased runoff could cause flooding downstream; (v) when plant and animal wastes are used to produce fuel, these cannot be added to the soil as fertilizer and a soil without fertilizer is depleted of nutrients and produce fewer crops; (iv) biomass contains less energy than a similar volume of fossil fuels.

\section{Hydrogen production routes from biomass}

The chemical structure and main organic components in biomass are very important in the development of processes for producing fuels and valuable chemicals[11]. The chemical components of the lignocellulose are divided into four major components: cellulose, hemicellulose, lignin and extractives [12]. Generally, the first three components have high molecular weights and contribute much mass, while the last component is of small molecular size, and available in little quantity [13]. Hydrogen can be produced from biomass, but this technology needs further development. The production of $\mathrm{H}_{2}$ from biomass has many advantages [14]. such as the independence from oil imports, stable pricing level, the $\mathrm{CO}_{2}$ balance improved by around $30 \%$.

The processes available for $\mathrm{H}_{2}$ production from biomass are divided into two categories: thermochemical and biological routes. Hydrogen can be produced from bio-renewable feedstocks by thermochemical conversion processes such as gasification, steam gasification, pyrolysis, steam reforming of bio-oils, and also supercritical water gasification. Biological hydrogen production can be classified into the following groups: (i) biophotolysis of water using green algae and blue-green algae (cyanobacteria), (ii) photo-fermentation, (iii) darkfermentation, and (iv) hybrid reactor system. The advantage of the thermochemical process is that its overall efficiency (thermal to hydrogen) is higher ( $\eta \approx$ $50 \%$ ) and production cost is lower [15]. The $\mathrm{H}_{2}$ yield that could be obtained from biomass is low, $15-18 \%$, based on dry biomass weight [15]

\subsection{Hydrogen production from biomass by gasification process}

At temperatures of approximately $600-900^{\circ} \mathrm{C}$, the biomass undergoes thermal decomposition and forms gas-phase products that usually contains $\mathrm{CO}, \mathrm{H}_{2}, \mathrm{CO}_{2}$, $\mathrm{CH}_{4}, \mathrm{H}_{2} \mathrm{O}$, and other gaseous hydrocarbons $\left(\mathrm{C}_{2}-\mathrm{C}_{7}\right)$ [16]. Composition of gas product resulted from the biomass gasification depends on the gasification process, agent of gasifying, and the composition of the feedstock [17]. $B$ iomass gasification is generally given by the reaction:

B iomass $+\mathrm{O}_{2}\left(\right.$ or $\left.\mathrm{H}_{2} \mathrm{O}\right) \rightarrow \mathrm{CO}, \mathrm{CO}_{2}, \mathrm{H}_{2} \mathrm{O}, \mathrm{H}_{2}, \mathrm{CH}_{4}+\mathrm{C}_{2}$ ${ }_{7}+$ char +tar + ash

In a gasification process that uses biomass as a feedstock, the first step is a thermos-chemical decomposition of the cellulose, hemicellulose and lignin compounds with the production of char, tar and volatiles [18]. Further the gasification of char and tar determines some other equilibrium reactions to be possible to occur. The possible products resulted from a gasification process are shown in Fig. 3 [19].

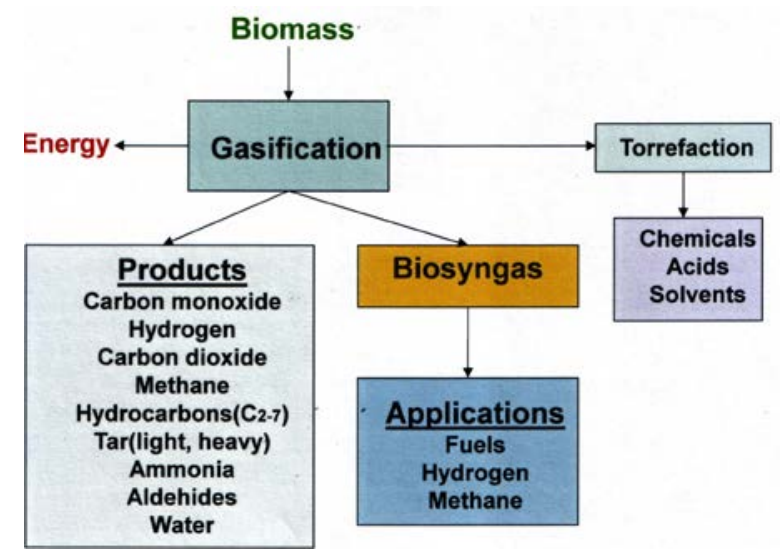

Figure 3. Possible products obtained from a gasification process.

When the biomass is gasified, the tar that is formed together with the gas phase is difficult to separate and remove with a physical dust removal method [20]. The distribution of the products and gas composition depend on many parameters including the temperature of gasification and the reactor type. The most common 
gasifier types are fixed bed (updraft, downdraft or horizontally fixed beds), fluidized bed, and also entrained flow gasifiers. All these gasifiers need to include significant gas conditioning along with the removal of tar and inorganic impurities and the subsequent conversion of $\mathrm{CO}$ to $\mathrm{H}_{2}$ by water gas shift reaction. Table 1 presents the typical gas composition data as resulted from wood and charcoal downdraft gasifier that operates on low to medium moisture content biomass [21]

Table 1. Gas composition data as obtained from wood and charcoal downdraft gasifiers operated on low to medium moisture content fuels (wood 20\%, charcoal 7\%) [21].

\begin{tabular}{|c|ccccc|c|}
\hline Comp & $\mathrm{H}_{2}(\%) \mathrm{CO}_{2}(\%) \mathrm{CH}_{4}(\%)$ & $\mathrm{CO}(\%) \mathrm{N}_{2}(\%)$ & $\begin{array}{c}\mathrm{HV} \\
\left(\mathrm{M} \mathrm{J} / \mathrm{m}^{3}\right)\end{array}$ \\
\hline W gas & $12-20$ & $9-15$ & $2-3$ & $17-22$ & $50-54$ & $5-5.9$ \\
\hline C gas & $4-10$ & $1-3$ & $0-2$ & $28-32$ & $55-65$ & $4.5-5.6$ \\
\hline
\end{tabular}

\section{Source: Ref.[21]}

Gasification processes provide the possibility to transform renewable biomass feedstocks into clean gas fuel or synthesis gas. The synthesis gas includes mainly $\mathrm{H}_{2}$ and $\mathrm{CO}$, also called as bio-syngas [22] and this is a gas rich in $\mathrm{H}_{2}$ and $\mathrm{CO}$ produced by gasification process of biomass. $\mathrm{B}$ io-syngas can be obtained from biomass by non-catalytic,catalytic, and also steam gasification processes. The steam gasification of biomass is a promising process used for thermos-chemical $\mathrm{H}_{2}$ production. The steam reforming and so-called dry or $\mathrm{CO}_{2}$ reforming are usually promoted by the use of catalysts and occur according to the following reactions:

$$
\begin{aligned}
& \mathrm{CnHm}+n_{\mathrm{H}} \mathrm{O} \leftrightarrow \mathrm{CO}+(\mathrm{n}+\mathrm{m} / 2) \mathrm{H}_{2} \\
& \mathrm{C}_{\mathrm{n}} \mathrm{H}_{\mathrm{m}}+\mathrm{nCO}_{2} \leftrightarrow(2 \mathrm{n}) \mathrm{CO}+(\mathrm{m} / 2) \mathrm{H}_{2}
\end{aligned}
$$

Conversion of biomass to synthesis gas by steam gasification is a challenge because of the diversity of the raw material (structure, composition, physical properties, reactivity, etc.) and because of the severe parameters (temperature, heating rate, residence time, biomass/catalyst ratio, etc.) that are required [23]. The $\mathrm{H}_{2}$ yield obtained from steam gasification process increases with increasing water-to-biomass ratio (W/S). The yields of $\mathrm{H}_{2}$ resulted from the pyrolysis and the steam gasification processes increase with increasing of temperature. Usually, the gasification temperature is higher than that of pyrolysis[24]. Also, the effect of catalyst on gasification products is very important, the use of the catalyst do not affect the gas yields, but the gas composition is strongly influenced, in the sense that the $\mathrm{H}_{2}$ and $\mathrm{CO}_{2}$ content increases, while that of $\mathrm{CO}$ decreases.

\subsection{Hydrogen production from biomass by pyrolysis process}

In the recent years, hydrogen production by biomass pyrolysis and/or gasification became a subject large researched in the field of biomass utilization[25]. Previous studies $[26,27]$ have reported that the steam introduction during biomass gasification process has resulted in an increasing of $\mathrm{H}_{2}$ yield due to the tar and higher hydrocarbon reforming, as well as the water gas shift reaction. Using the steam as an oxidizer, the following chemical reaction can be written:

$$
\mathrm{CH}_{1.31} \mathrm{O}_{0.69}+1.31 \mathrm{H}_{2} \mathrm{O} \rightarrow 1.97 \mathrm{H}_{2}+\mathrm{CO}_{2}
$$

with the biomass chemical formula calculated from the elemental analysis, Table 2.

Table 2. Proximate and ultimate analyses of walnut shells

\begin{tabular}{|c|c|c|c|}
\hline Element & UA (wt.\%) & \multicolumn{2}{|c|}{ PA (wt.\%) } \\
\hline $\mathrm{C}$ & 49.26 & fixed carbon & 10.76 \\
\hline $\mathrm{H}$ & 5.38 & moisture & 7.85 \\
\hline $\mathrm{O}$ & 45.08 & volatiles & 80.21 \\
\hline $\mathrm{N}$ & 0.28 & ash & 1.18 \\
\hline
\end{tabular}

According to reaction (4), a minimum of steam/biomass (S/B) ratio of 0.97 is determined for the theoretical maximum $\mathrm{H}_{2}$ yield. In the present the researches are mostly focused on varying operating parameters, using different types of reactor, using various types of catalysts, etc. $[25,26,27]$. U nfortunately, a little attention is considered to reducing the cost through improving the steam supply mode [27] even if it consumes a large quantity of energy of the whole process. Normally, the raw biomass contains a big amount of moisture, which even exceeds $50 \mathrm{wt} \%$ (wet basis). In the conventional biomass steam gasification (CBSG) such moisture is removed through a pre-drying process before gasification. Then, the pre-dried biomass is gasified with steam, which is usually obtained from an auxiliary system (steam generator or boiler). B oth the pre-drying process and the steam generation involve high energy consumption and make CBSG process more expensive and complex. From all of these considerations, in this part of paper a method of hydrogen-rich gas production by biomass pyrolysis in an autogenerated steam atmosphere is proposed. In this method, the biomass with high moisture content is directly used as feedstock of pyrolysis reactor. The method utilizes steam autogenerated from biomass moisture as a reactant to combine with the intermediate products resulted from the pyrolysis process to produce additional gas (hydrogen). In the present work, to obtain some basic informations, the effect of several parameters such as pyrolysis temperature, heating rate, moisture content, and stripping gas flow on the pyrolysis process was investigated. The residual biomass, including walnut shell (WS) was employed as raw material in this study. The raw walnut shells in hemispherical shape with about $25 \mathrm{~mm}$ diameter and $3 \mathrm{~mm}$ thickness were supplied by the Research Station for Fruit Growing Valcea. These were grinded at a particle size: $<0.15 \mathrm{~mm}$. The proximate analyses of raw walnut shells was done according to ASTM D3174-04 for ash analysis and ASTM D3175-89a for volatile matter. The ultimate analysis to determine the quantity of $\mathrm{C}, \mathrm{H}, \mathrm{N},(\mathrm{O}$ calculated from difference) was made according to ASTM D5291-96 using a FLA SH-2000 Elemental A nalyzer. All chemicals used in this study were of analytical grade. To study the effect of 
moisture content, the walnut shells were dried naturally, by sun drying to different moisture contents: (a) wet walnut shell sample,W SW, the as-received walnut shell, with a moisture content of $\approx 47.37 \mathrm{wt} \%$ (wet basis); (b) a partially pre-dried fraction of the as received wet walnut shell sample, WSPD, with a moisture content of $\approx 33.68 \mathrm{wt} \%$ (wet basis); and (c) totally pre-dried walnut shell sample, WSTD, with a moisture content of $\approx 7.85 \mathrm{wt} \%$ (wet basis).

\section{Conclusions}

B iomass represents a vaste renewable energy source and there are various ways by which biomass energy can be converted into fuels. The technologies used for extracting the energy from biomass as well as the advantages and disadvantages that appear by using of biomass as a energy source were presented in this study. In addition, hydrogen-rich gas production from biomass pyrolysis in an autogenerated steam atmosphere was studied. The tests were carried out to establish the influence of some process parameters (such as the reactor temperature, moisture content, flow rate of the stripping gas, and also the heating rate) on the pyrolysis process and hydrogen content from gas product. The obtained results lead to the following conclusions: (i) The direct pyrolysis of wet biomass without step of predried treatment promotes hydrogen-rich gas production. Under the condition of fast-heating rate (fast pyrolysis) and without the using of N2 stripping gas, the pyrolysis of WSW sample releases higher $\mathrm{H} 2$ yield than those released from W STD sample;(ii) In order that the steam resulting from its own moisture content of the biomass to be used to produce additional hydrogen, a high heating rate is required (fast pyrolysis) because under fast-heating conditions, both drying and pyrolysis steps can occur in a shorter time and thus are improved the interactions between the autogenerated steam and the intermediate products (volatile and char) and more hydrogen is produced; (iii) The stripping gas flow rate greatly influence the hydrogen yield. With the decreasing of the stripping gas flow rate the hydrogen amount increases, this being much more evidente in the case of fast pyrolysis process, because higher reactor temperature favors hydrogen production; (iv) This study demonstrates that a new steam supply way is possible by combination of the predrying step with the autogenerated steam step and thus makes this method much more economic.

The financial Support for conducting of this research was provided by the Ministry of Research and Innovation from Romania, National Plan of Research \& Development in Energy and Environmental field. Project no. PN 191103 01//2019

\section{References}

1. D. Klass, An Introduction to Biomass Energy a Renewable Resource (www.beral.org)

2. T.N. Veziroglu, S.Sahin.,. Energy Convers Manage, 49 (2008)

3. M. B alat, Int J Hydrogen Energ 33(2008);

4. S.V. M ohan, Y.V.B haskar,P.N. Sarma, W ater Res ., 41(2007)

5. D. Das, N. Khanna, T.N. Veziroglu, Chem Ind Chem Eng Q, 14(2008)

6. S.Y olcular, Energy Sources Part A, 31(2009)

7. Biomass-The Growing Energy Source, (www.science. org.au/ nova)

8. M. B alat, Energy Sources Part B, 2(2007)

9. S.Y aman, Energy Convers M anage, 45(2004)

10. A. Demirbas, Energy Sources Part A, 31(2009)

11. A. Demirbas, Energy Sources Part A, 30(2008)

12. S.M .Swami, V. Chaudhari,D.S. Kim, S.J .Sim,M .A. A braham, Ind Eng Chem Res, 47(2008)

13. H. B alat, Energy Educ Sci Technol Part A, 24(2010)

14. M. B alat, Energy Sources Part A, 30(2008)

15. M.F. Demirbas, A ppl Energy, 86(2009)

16. S.J.Y oon, Y.C.Choi, J.G.Lee, Energy Convers $M$ anage, 51(2010)

17. H.E.M. Stassen, H.A.M.Knoef, Biomass Technology Group, University of Twente; 1993.

18. A.H. Demirbas, Energy Educ Sci Technol Part A, 26(2010)

19. C. Dupont, G.Boissonnet, J.M.Seiler, P.Gauthier, D.Schweich, Fuel, 86(2007)

20. M. Ni, Y.C.L. Dennis, K.H.L. M ichael, K. Sumathy, Fuel Process. Technol. 87( 2006)

21. P.M. LV, J. Chang, Z.H. Xiong, H.T. Huang, C.Z. Wu, Y. Chen, J.X. Zhu, Energy Fuels 17(2003)

22. S.T.Chaudhari, A.K. Dalai, N.N. B akhshi, Energy Fuels, 17( 2003)

23. M.R.M ahishi, D.Y. Goswami, J. Int. J. Hydrogen Energy, 32( 2007)

24. A.E. Pűtűn, E. Apaydın, E. Pütün, Energy, 27( 2002)

25. E.A paydi-Varol, E.Pütűn, A.E. Pütűn, Fuel, 86(2007)

26. E.Pütün , B.B. Uzun, A.E. Pütün , Bioresour. Technol. , 97(2006)

27. A.Dominguez, J.A. Menendez, J.J. Pis, J. A nal. Appl. Pyrolysis, 77( 2006) 